\title{
Application of ICP-MS to Examining the Utility of Skin as a Monitoring Tissue for Trace Elements in Bottlenose Dolphin, Tursiops Truncatus
}

\author{
Colleen E. Bryan ${ }^{*}{ }^{1,2}$, Steven J. Christopher ${ }^{1}$, William A. McLellan ${ }^{3}$, Wayne E. McFee ${ }^{4}$, \\ Lori H. Schwacke ${ }^{5}$ and Randall S. Wells ${ }^{6}$
}

\author{
${ }^{I}$ National Institute of Standards and Technology, Hollings Marine Laboratory, 331 Fort Johnson Road, Charleston, \\ South Carolina, 29412, USA \\ ${ }^{2}$ College of Charleston, Grice Marine Laboratory, 205 Fort Johnson Road, Charleston, South Carolina 29412, USA \\ ${ }^{3}$ Department of Biology and Marine Biology, University of North Carolina Wilmington, 601 South College Road, \\ Wilmington, North Carolina, 28403, USA \\ ${ }^{4}$ Center for Coastal Environmental Health and Biomolecular Research, National Ocean Service, National Oceanic and \\ Atmospheric Administration, 219 Fort Johnson Road, Charleston, South Carolina, USA \\ ${ }^{5}$ National Ocean Service, Hollings Marine Laboratory, 331 Fort Johnson Road, Charleston, South Carolina, 29412, \\ USA \\ ${ }^{6}$ Chicago Zoological Society c/o Mote Marine Laboratory, 1600 Ken Thompson Parkway, Sarasota, Florida, 34236, \\ USA
}

\begin{abstract}
Collision cell technology inductively coupled plasma mass spectrometry (CCT-ICP-MS) was applied to answer fundamental questions about the utility of bottlenose dolphin skin as a monitoring tissue for trace element concentrations. Bottlenose dolphin skin samples were obtained from two freshly dead animals during necropsies. The samples were collected from twelve standardized locations across each animal, representing a significant spatial surface area to test among site trace element concentration variability. Skin biopsy samples were analyzed for $\mathrm{As}, \mathrm{Cd}, \mathrm{Cu}, \mathrm{Mn}, \mathrm{Mo}, \mathrm{Pb}, \mathrm{Rb}$, $\mathrm{Se}, \mathrm{Sr}, \mathrm{V}$ and $\mathrm{Zn}$ concentrations by CCT-ICP-MS, and $\mathrm{Hg}$ concentrations were separately measured by atomic fluorescence spectrometry (AFS). Wet mass concentrations ranged from $>100 \mu \mathrm{g} / \mathrm{g}$ ( $\mathrm{Zn}$ ) to $<0.0100 \mu \mathrm{g} / \mathrm{g}$ (V, Mo, Cd, and $\mathrm{Pb}$ ). Relative standard deviations of less than $20 \%$ among sample sites were observed for $\mathrm{Cu}, \mathrm{As}, \mathrm{Se}, \mathrm{and} \mathrm{Hg}$, demonstrating that deposition of these elements may be tightly regulated in skin tissue. Multifactor mixed-effect analysis of variance analyses (ANOVA) showed significant effects $(\mathrm{p}<0.05)$ longitudinally (dorsal-ventral) for $\mathrm{Cu}, \mathrm{Mo}, \mathrm{Ru}, \mathrm{Se}$, $\mathrm{V}$, and $\mathrm{Zn}$ indicating that standardized sample collection sites may be needed for comparative evaluation of these elements between animals, due to relatively heterogeneous distribution in skin.
\end{abstract}

Keywords: Trace elements, skin, monitoring tissue, bottlenose dolphin, Tursiops truncatus, ICP-MS, AFS.

\section{INTRODUCTION}

Skin is often proposed as a suitable sampling compartment to study distributions, concentrations, or types of contaminants in cetacean species given the necessity of non-invasive, non-lethal sample collection for living, protected animals, and the importance of post mortem examination and sampling from stranded or by-catch animals. The National Oceanic and Atmospheric Administration (NOAA) has invested considerable resources into developing projects that study the bottlenose dolphin (Tursiops truncatus) as a sentinel for contaminants and ecosystem health monitoring in coastal marine environments. Live capture events provide more flexibility in the types and quantity of non-invasive tissues collected, however they are costly, labor intensive, and may not be

*Address correspondence to this author at the National Institute of Standards and Technology, Hollings Marine Laboratory, 331 Fort Johnson Road, Charleston, South Carolina, 29412, USA; Tel: +1 843762 8832; Fax: +1 843762 8742; E-mail: colleen.bryan@nist.gov possible in all dolphin habitats. Remote biopsy techniques offer a more cost effective and less logistically challenging alternative to cetacean sample collection, yet the tissue mass available for analyses is limited. For trace element measurements, these monitoring efforts can impose significant analytical challenges. Skin collected either through live-capture wedge-biopsy or remote dart biopsy is of limited mass. Each skin and blubber biopsy is typically divided between analyses for genetic determinations, carbon and nitrogen stable isotope measurements, organic contaminant analyses, and trace element analyses, including mercury. This sample division relegates very small quantities of sample for trace element measurements, which dictates employment of high sensitivity, multi-element instrumental methods to fully leverage the analytical samples. Inductively coupled plasma mass spectrometry (ICP-MS) possesses the necessary low detection limit and multi-element analysis capabilities required for dolphin skin analyses. The National Institute of Standards and Technology (NIST) routinely applies CCT-ICP-MS for various ongoing biomonitoring and health assessment efforts related to retrospective and real 
time analyses of marine mammal tissues collected under the NOAA Office of Protected Resources Marine Mammal Health and Stranding Response Program. The capabilities of CCT-ICP-MS were used in this study to help answer some fundamental questions about the utility and representativeness of dolphin skin as an environmental monitoring tissue.

Little is known about the physiological functions and composition of trace elements in cetacean skin. Skin is the largest and one of the most important organs, acting as a protective barrier [1], and skin condition is a sensitive indicator of overall health status. Cetacean skin exhibits decreased drag due to the absence of hair and surface glands [2]. The lack of these features prevents excretion and uptake of trace elements through openings in skin, making cetaceans a relatively closed system. Yang et al. [1] determined in Dall's porpoise (Phocoenoides dalli) that trace elements mainly accumulate in the multi-layered epidermis and dermis. The blubber layer acts to somewhat isolate skin from the rest of the body resulting in reduced exchange of trace elements to the epidermis. The high lipid content in blubber limits the deposition of trace elements in this tissue since many elements are not lipophilic [1]. Certain body regions, such as the dorsal fin, have higher concentrations of superficial blood vessels used for thermoregulation and could potentially receive more trace elements with increased blood flow [3]. Skin molting patterns may also lead to variations in trace element concentrations. For example, belugas (Delphinapterus leucas) and narwhals (Monodon monoceros) lose approximately $13 \%$ to $20 \%$ of the total mercury in skin through molting annually $[4,5]$. This needs to be taken into consideration since migratory populations have seasonal changes in diet that could result in seasonal variations in skin trace element accumulation [6]. Bottlenose dolphins (Tursiops truncatus) have a relatively long turnover time and fast sloughing rate of epidermal cells. Hicks et al. [7] have estimated that it takes about 73 days for bottlenose dolphin epidermal skin cells to travel approximately $1.2 \mathrm{~mm}$ from the basal layer to the surface, and the outer most cell layer sloughing rate is 12 times per day. Individuals that spend more time in lower salinity water have increased skin sloughing rates.

Cetacean skin physiology is unique relative to other mammals, allowing for distinct trace element accumulation and shedding patterns. Previous studies have shown that some elements, such as mercury, are not homogeneously distributed on a micro-scale level, between dermal layers. As an example, the outer-most layer of skin has been demonstrated to maintain the greatest mercury concentrations in belugas and narwhals $[4,5]$. Differences in trace element concentrations among geographic areas and regional patterns have been used to assist with stock delineation for some species. Kunito et al. [8] used trace elements in skin as chemical tracers to identify separate stocks of minke whale (Balaenoptera bonaerensis) in the southern hemisphere.

Other applications for skin trace element concentration data include long-term biomonitoring studies and studies focused on assessing changes in feeding ecology, habitat utilization, and animal health. Skin has been proposed as an alternative marker for evaluating bioaccumulation of trace elements in internal organs and as a long-term monitoring tool for populations and individual animals [9]. Skin can be collected in a non-lethal manner and therefore is being considered for monitoring ecological changes in trace element concentrations and their impact on free-ranging bottlenose dolphin populations. Skin is always collected when wedge and dart blubber biopsies are taken, which has the potential to allow for the assessment of various trace elements in live animals. Currently, published data are deficient for a broad suite of trace elements in bottlenose dolphin skin. Baseline work in this area was performed recently in the Sarasota Bay, FL population by Bryan et al. [10] and in the Charleston, SC and Indian River Lagoon, FL populations by Stavros et al. [11]. During live capture and release health assessment operations, wedge biopsies are obtained surgically after administration of local anesthetic. Dart biopsies are obtained using a crossbow or rifle to shoot darts with a collecting tip threaded onto the end. After impact, the dart rebounds off the animal into the water and is retrieved with the sample in the collecting tip. Many published studies do not indicate a standardized location when skin is obtained from a live or stranded animal, and dart biopsies inherently possess a greater potential for location variation. Our research indicates a greater need for biopsy location and collection standardization among studies. A few trace element and organic contaminant studies that have indicated a standardized sampling region for biopsy collection include Reddy et al. $[12,13]$ from $10 \mathrm{~cm}$ lateral to the anterior insertion of the dorsal fin of bottlenose dolphin, Yang et al. [1] from the cervical region near the left flipper of Dall's porpoise, Wells et al. [14, 15] from below the caudal insertion of the dorsal fin of bottlenose dolphin, and Schwacke et al. [16], Bryan et al. [10], and Stavros et al. [11] from $10 \mathrm{~cm}$ posterior to and $10 \mathrm{~cm}$ ventral to the posterior aspect of the dorsal fin of bottlenose dolphin.

Studies such as those cited above need to be complemented by more fundamental research designed to answer basic questions about trace element concentration variability. In the absence of such information, researchers must assume a priori that spatial deposition patterns of trace elements in skin are consistent and reproducible, and that concentrations are homogenous and representative across a single animal and/or regional population of dolphins. No studies have comprehensively examined trace element homogeneity on a macro-scale, assessing concentrations across an animal's entire body, which is the focus of the present work. Such fundamental research is needed to fully evaluate the utility of skin samples for biomonitoring of trace elements before significant resources are directed into intense field sampling efforts that are underpinned by significant analytical support investments. This study leverages a rare opportunity to collect skin tissue samples across the skin surface of two bottlenose dolphins to address whether or not trace element levels in bottlenose dolphin skin are homogenously distributed on a macro-scale across an animal's entire body, or if there is severe heterogeneity that would preclude the use of skin from differing anatomical regions as a reliable non-lethal monitoring compartment. 


\section{MATERIALS AND METHODS}

\subsection{Sample Collection}

Skin samples for trace element homogeneity testing were collected from twelve standardized locations across each body of two freshly dead bottlenose dolphins (Fig. 1). The sample sites on the animals were divided into two types of transects: lateral and longitudinal. The lateral transects, depicted by letter codes B, C, D, and E in Fig. (1), were oriented vertically dividing the animal into planes around the girth anterior to posterior. The longitudinal transects, depicted by number codes 1,2 , and 3 run lengthwise, dividing the animal into planes dorsal to ventral. Samples E1, E2, and E3 were collected posterior to the anus. The first samples were collected (under the National Marine Fisheries Service Scientific Research Permit No. 522-1569 issued to R.S. Wells) from an elderly male dolphin that was extremely ill and died during health assessment operations in November 2002 in Sarasota Bay, FL. The second animal was an adult female that stranded freshly dead in January 2004 on Kiawah Island, SC. The samples were collected during a thorough necropsy of each animal. Each sample was obtained using a set of pre-cleaned stainless steel implements. The biopsies were rectangular, measuring approximately $4 \mathrm{~cm}$ long by $4 \mathrm{~cm}$ wide by $1.5 \mathrm{~cm}$ deep. The skin intact with the blubber was stored in separate polytetrafluoroethylene (PTFE) $15 \mathrm{~mL}$ jars or bags and frozen $\left(-150^{\circ} \mathrm{C}\right)$.
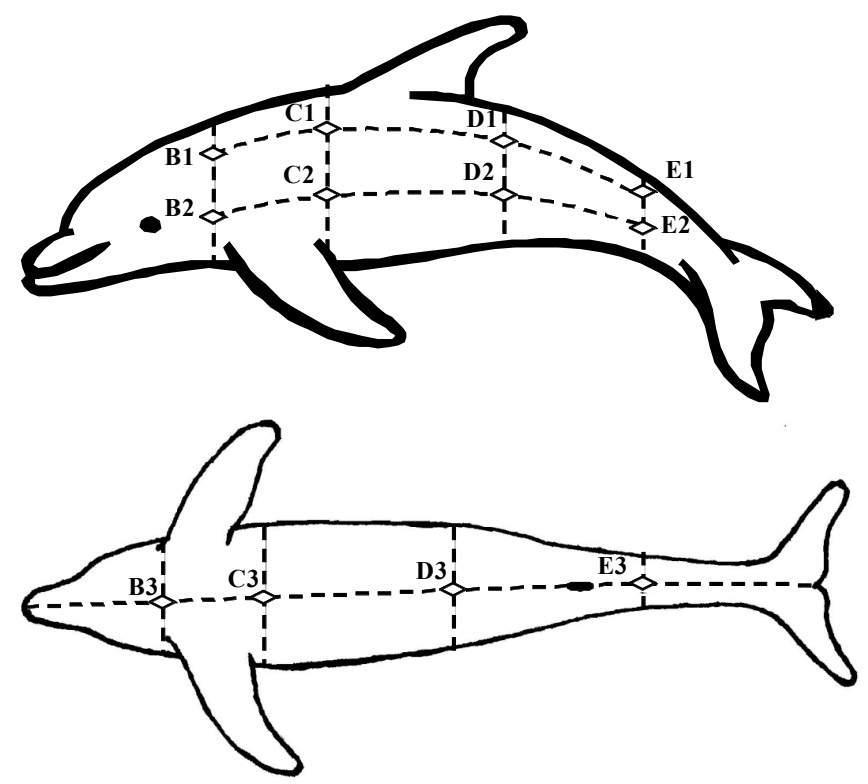

Fig. (1). Skin biopsy locations for trace element homogeneity sampling. Locations B1 through B3 were collected anterior to the pectoral fin. Locations $\mathrm{C} 1$ through $\mathrm{C} 3$ were collected posterior to the pectoral fin. Location D1 was collected $10 \mathrm{~cm}$ posterior and 10 $\mathrm{cm}$ ventral from the posterior aspect of the dorsal fin. Locations E1 through E3 were collected posterior to the anus.

\subsection{Sample Preparation}

The analytical methods associated with this study make use of highly acidic, caustic, toxic chemicals and biohazard materials that required use of personal protective equipment; appropriate safety protocols were followed. The epidermis from the twelve samples collected from each of the two freshly dead animals indicated above was thawed and carefully dissected away from the blubber layer on a PTFE cutting board using a clean set of stainless steel implements for each sample. The instruments used for tissue dissection were cleaned using high-purity deionized water (resistivity $=$ $18 \mathrm{M} \Omega-\mathrm{cm}$ ) and methanol certified for trace metal analysis (Burdick and Jackson, Muskegon, MI), and clean powder free vinyl gloves were worn at all times. The skin for trace element analysis was rinsed with high-purity deionized water from a PTFE squirt bottle, sub-sampled, and then placed into a polypropylene cryogenic vial and frozen $\left(-80{ }^{\circ} \mathrm{C}\right)$ until analysis. The sample dissolution procedure utilized acid assisted microwave digestion (CEM MARS-5 Xpress, CEM Corporation, Matthews, NC). An approximately $0.5 \mathrm{~g}$ full epidermal thickness sample was digested in a decomposition medium of $7 \mathrm{~mL}$ of high purity concentrated nitric acid $\left(\mathrm{HNO}_{3}\right)$ (Fisher Scientific, Suwanee, GA). SRM 1946 Lake Superior Fish Tissue (NIST, Gaithersburg, MD), DORM-2 Dogfish Muscle (NRC Canada, Ontario, CA) and Seronorm Level 3 Human Whole Blood (Sero, Oslo, Norway) control samples and procedural blanks were digested concurrently with the unknown samples. All samples were weighed by difference into pre-cleaned PTFE microwave decomposition vessels and spiked with internal standards. Additionally, aliquots of an in-house prepared dolphin skin control material (serving as the calibration standard) were spiked with a multi-element spike solution derived by mixing and diluting analyte solutions from the NIST SRM 3100 Series of single-element solution standards.

The operating conditions of the microwave were programmed as follows: 1200 watts of applied power; 20 minute ramp to $210^{\circ} \mathrm{C}$; and 10 minute hold at $210^{\circ} \mathrm{C}$. After digestion, the resultant digests were vented, the solutions were quantitatively transferred, and diluted to $90 \mathrm{~g}$ using high-purity deionized water. The first dilution was used directly for ICP-MS analysis, and a $5 \mathrm{~g}$ aliquot of the first dilution was further diluted with high-purity water to $60 \mathrm{~g}$ for atomic fluorescence spectrometry (AFS) analysis to eliminate matrix effects.

\subsection{Instrumental and Calibration Methods}

Concentrations of 12 trace elements (As, $\mathrm{Cd}, \mathrm{Cu}, \mathrm{Hg}$, $\mathrm{Mn}, \mathrm{Mo}, \mathrm{Pb}, \mathrm{Rb}, \mathrm{Se}, \mathrm{Sr}, \mathrm{V}$, and $\mathrm{Zn}$ ) were measured in bottlenose dolphin skin samples at the National Institute of Standards and Technology (NIST), in Charleston, SC. The elements were chosen based on nutritional value, toxicity, and sample pre-screening. All elements except mercury were measured on a ThermoElemental X-7 ICP-MS (Thermo Elemental, Franklin, MA). The collision cell gases employed were metered mixtures of $8 \% \mathrm{H}_{2}$ in balance He operating at a flow rate of $8 \mathrm{~mL}$ per min and $1 \% \mathrm{NH}_{3}$ in balance $\mathrm{He}$ operating at a flow rate of $6 \mathrm{~mL}$ per min. A solution containing $10 \mathrm{ng} / \mathrm{g} \mathrm{Co}$ and $10 \mathrm{ng} / \mathrm{g} \mathrm{In}$ in $2 \% \mathrm{HCl}$ was used to tune the system, which consisted of optimizing signal intensity and stability at m/z 59 for Co and 115 for In, while carefully monitoring and minimizing the background contributions at $\mathrm{m} / \mathrm{z} 51\left(\mathrm{OCl}^{+}\right), \mathrm{m} / \mathrm{z} 56\left(\mathrm{ArO}^{+}\right), \mathrm{m} / \mathrm{z} 75$ $\left({ }^{40} \mathrm{Ar}^{35} \mathrm{Cl}^{+}\right)$, and $\mathrm{m} / \mathrm{z} 80\left({ }^{40} \mathrm{Ar}_{2}{ }^{+}\right)$mitigated by the collision cell gases. The ICP-MS instrument was configured to perform acquisitions in several modes, depending on the element monitored. Zinc isotopes ( $\mathrm{Rh}$ internal standard) were measured at an increased resolution of approximately 
$0.35 \mathrm{am} \mu$ due to the high $\mathrm{Zn}$ concentrations in the samples, whereas the remaining elements (As, $\mathrm{Cd}, \mathrm{Cu}, \mathrm{Mn}, \mathrm{Mo}, \mathrm{Pb}$, $\mathrm{Rb}, \mathrm{Se}, \mathrm{Sr}$ and $\mathrm{V}$ ) and several associated internal standards ( $\mathrm{Au}, \mathrm{In}, \mathrm{Nb}, \mathrm{Ru}$ and $\mathrm{Y}$ ) were measured at unit mass resolution in standard mode $(\mathrm{Mn}, \mathrm{Pb}, \mathrm{Rb}, \mathrm{Sr})$ or one of two appropriate collision cell modes; ammonia gas for $\mathrm{V}$ and hydrogen gas for the remaining elements. Mercury was measured via atomic fluorescence spectrometry using a Millenium Mercury Analyzer (PS Analytical, Kent, England) due to long washout memory on the ICP-MS. SRM 3133 Mercury Spectrometric Solution (NIST, Gaithersburg, MD) served as the calibrant for quantification of mercury using external calibration.

A matrix-matched calibration approach using the method of standard additions was employed for quantification. An in-house cryogenically homogenized dolphin skin quality control material (see Bryan et al. [10]) was used to build the matrix-matched standard addition curves using several concentration levels of analytical spike and all elements of interest were referenced to appropriate internal standards. The calibration curve response (slope) established using dolphin skin control material was used in conjunction with the resultant analytical sample signals to determine trace element concentrations in the body location samples, certified reference materials (CRMs), and procedural blanks. External calibration methods with acid-matched calibrants and samples were used for $\mathrm{Hg}$ analysis by AFS. The analytical method and validation scheme have been described in detail by Christopher et al. [17] and Bryan et al. [10].

\subsection{Statistical Analyses}

Statistics were performed using JMP 4 (SAS Institute Inc., Cary, NC) and Microsoft Excel (Microsoft Inc., Redmond, WA). The assumptions of data normality and equal variance were tested using the Shapiro-Wilk goodness of fit test for normality and the Levene median test for equal variance, prior to performing analyses of variance (ANOVA) on the skin concentration data. If either the normality or equal variance test failed, the data were natural log transformed before further analysis. It must be emphasized that this is the first study of its kind to assess across body skin concentration homogeneity for trace elements in bottlenose dolphins, although the study is ultimately limited by the opportunistic sampling of a small number of whole animals. Undoubtedly, the number of subjects $(n=2)$ will not satisfy minimum sample size requirements for many parametric or non-parametric tests; $p$ values may be biased, and any tests performed will lack statistical power, especially for non-parametric tests. Given these caveats, parametric, mixed-effect ANOVA test methods were chosen to analyze the differences among means of individual trace element concentrations, including the factors of lateral and longitudinal body planes, for the purposes of detecting preliminarily, spatial trends in the trace element concentration data that could have an impact on various long term environmental monitoring programs related to NOAA's marine mammal monitoring activities. Individual animals were treated as a random effect and both lateral and longitudinal planes were treated as fixed effects. Differences in trace element concentrations between individuals could be influenced by age, sex, season, water temperature, salinity, and temporal location. Effects of these factors on elemental concentrations were minimized by treating the individual animals as a random effect in the statistical analyses. If either of the fixed effects were found to be significant, then a Tukey honestly significantly different (HSD) test and least square (LS) mean plot were performed to determine how the means varied within an effect. A custom Labview ${ }^{\mathrm{TM}}$ (National Instruments, Austin, TX) program was developed to create spatial trace element concentration color maps to assist with data interpretation.

\section{RESULTS AND DISCUSSION}

\subsection{CCT-ICP-MS Method Validation and Quality Control}

Multiple CRMs were used to obtain concentration values for each element of interest and to test the robustness of the calibration scheme wherein skin matrix served as the calibration curve. Cryohomogenized dolphin skin was used to build the matrix-matched standard additions calibration curves to allow quantification of trace elements in unknown skin samples based on the method of standard additions with internal standards. For each batch of samples, the slope of the established skin calibration curve was divided by corrected analyte/internal standard response data obtained for the unknown dolphin skin samples to obtain concentration estimates without having to build a standard additions curve for every individual sample. Similarly, the skin calibration curve slopes and the measured analyte responses from control samples and blanks were used to predict trace element concentrations in the respective samples. The data in Table 1 show that for most of the elements studied, the matrix-matched skin calibration curve produced reasonable concentration estimates for trace elements in the differing matrix control materials, demonstrating commutability of the skin-based calibration curve and the robustness of the ICP source. Certain elements such as As and Se were expected to produce poorer concentration estimates given the poor matrix matching between skin and CRM material types, as these elements are more sensitive to differential ionization effects when the carbon content is not matched between samples and standards.

\subsection{Distribution of Trace Elements in Skin}

Concentrations of the 12 elements measured in the 24 skin samples from the two biopsied bottlenose dolphins are shown in Table 2. Sample D3 (Fig. 1) from the South Carolina dolphin was not included in calculating the mean, standard deviation, coefficient of variation (CV), or ANOVAs for $\mathrm{Pb}$ due to this sample being determined as an outlier by a Q-test (Table 2). Sample D3 from the Florida dolphin was not an outlier indicating that sample D3 from the South Carolina animal was possibly contaminated with particulate $\mathrm{Pb}$. Zinc levels were greatest $(>100 \mu \mathrm{g} / \mathrm{g})$ relative to other elements studied in skin. A similar trend has been observed previously in other cetaceans including Dall's porpoise [1, 18], beluga [4], narwhal [4], and striped dolphin (Stenella coeruleoalba) [9, 19]. These relatively high $\mathrm{Zn}$ concentrations suggest skin could be an important organ for $\mathrm{Zn}$ deposition [1]. Zinc and Se are believed to play important roles in healing wounds and depositing new collagen to wound sites $[1,20,21]$. About $31 \%$ of the bottlenose 
Table 1. Mean ( \pm Expanded Uncertainty About the Mean or \pm [1 SD]) Trace Element Concentrations Measured in CRM Control Samples Using Dolphin Skin Calibration Curves

\begin{tabular}{|c|c|c|c|c|c|c|}
\hline Element & \multicolumn{2}{|c|}{ Seronorm Human Whole Blood ${ }^{a}$} & \multicolumn{2}{|c|}{ SRM 1946 Lake Superior Fish Tissue ${ }^{a}$} & \multicolumn{2}{|c|}{ DORM-2 Dogfish Muscle ${ }^{b}$} \\
\hline $\mathrm{Cr}$ & $9.3 \pm[4.21]$ & $11.0 \pm 1.3$ & & & $26.9 \pm[12.6]$ & $34.7 \pm 5.5$ \\
\hline Mn & $17.8 \pm[3.8]$ & $15.3 \pm 2.7$ & & & $3.26 \pm[0.92]$ & $3.66 \pm 0.34$ \\
\hline $\mathrm{Zn}$ & $3834 \pm[568]$ & $4532 \pm[267]$ & $2.70 \pm[0.89]$ & $3.10 \pm 0.18$ & $24.2 \pm[12.8]$ & $25.6 \pm 2.3$ \\
\hline As & $68 \pm[23]$ & $26 \pm 2$ & $0.348 \pm[0.040]$ & $0.277 \pm 0.010$ & $23.1 \pm[16.63]$ & $18.0 \pm 1.1$ \\
\hline $\mathrm{Se}$ & $177 \pm[22]$ & $168 \pm 10$ & $0.692 \pm[0.166]$ & $0.491 \pm 0.043$ & $3.11 \pm[0.42]$ & $1.40 \pm 0.09$ \\
\hline $\mathrm{Rb}$ & $1275 \pm[190]$ & $1223 \pm[16]$ & & & & \\
\hline $\mathrm{Hg}$ & & & $0.413 \pm[0.0981]$ & $0.433 \pm 0.009$ & $3,95 \pm[0.261]$ & $4.64 \pm 0.26$ \\
\hline $\mathrm{Pb}$ & $549 \pm[551]$ & $607 \pm 33$ & & & $0.049 \pm[0.012]$ & $0.065 \pm 0.007$ \\
\hline
\end{tabular}

Note: ${ }^{a}$ Wet mass fraction ; ${ }^{b}$ Dry mass fraction. ${ }^{c}$ The empty cells in this Table 1 are elements that were not measured in a CRM since a certified value is not available for the CRM. Thus, these cells were intentionally left blank.

dolphins in Sarasota Bay, FL possess shark bite scars indicating that wound healing had occurred in these scarred areas $[22,23]$. The small sample size of two animals in this study limits statistical analysis between $\mathrm{Zn}$ concentrations in skin and scar abundance, but future complementary data sets could shed light on correlations between zinc concentrations in skin and scar abundance. Additionally, high concentrations of $\mathrm{Zn}$ and Se may aid in photo-oxidative protection in guarding skin from solar damage [1, 24]. Selenium along with $\mathrm{Cu}$ protects skin cells against oxidative destruction by reactive oxygen species [20]. Mercury and Se concentrations were considerably greater in relationship to other trace element concentrations in bottlenose dolphin skin, with mean concentrations near $1 \mu \mathrm{g} / \mathrm{g}$. Similar skin Se concentrations have been reported for beluga and narwhal [4]. Mercury is a toxic element that is known to biomagnify in marine food chains and bioaccummulate in individuals. Since odontocetes feed at high trophic levels, high $\mathrm{Hg}$ burdens were expected [6]. Mercury concentrations in bottlenose dolphin skin in this study were similar to those reported for Pantropical spotted dolphins (Stenella attenuata) [25], belugas [4, 5], and striped dolphins [9].

Vanadium, $\mathrm{Mo}, \mathrm{Cd}$, and $\mathrm{Pb}$ concentrations were lower relative to other trace elements measured in bottlenose dolphin skin, with mean concentrations below $10 \mathrm{ng} / \mathrm{g}$. Similar skin concentration patterns for $\mathrm{V}, \mathrm{Mo}, \mathrm{Cd}$, and $\mathrm{Pb}$ have been found in Dall's porpoise [1]; as well as for $\mathrm{Cd}$ and $\mathrm{Pb}$ in striped dolphin [9], beluga, and narwhal [4]. Manganese, $\mathrm{As}, \mathrm{Sr}, \mathrm{Cu}$, and $\mathrm{Rb}$ mean concentrations were found at moderate concentrations compared to the other elements in bottlenose dolphin skin reflecting similar patterns reported for $\mathrm{Mn}, \mathrm{Sr}$, and $\mathrm{Cu}$ in Dall's porpoises [1]; and $\mathrm{Cu}$ in striped dolphins [9], belugas, and narwhals [4].

\subsection{Skin as a Monitoring Tissue for Trace Elements}

Trace element macro-homogeneity was tested in bottlenose dolphin skin samples by dividing the entire animal into body regions along one side and the ventral side; and collecting samples from each of the twelve regions (Fig. 1). The locations were standardized in a lateral and longitudinal grid to cover a large surface area and answer the fundamental question of how representative are the trace element patterns and concentrations across the body of an individual cetacean. Because of the limited number of animals available at the time of the study, the data and results are best interpreted in a limited context and extrapolation of the findings to population or life history trends should be avoided. Additionally, inter-animal comparison of trace element concentrations should not be attempted as the samples originate from only one animal in each of two distinct populations. In order to put absolute concentration data in context for environmental monitoring, concentration data from both individual animals were referenced to a specific sampling location (site D1). Sampling location D1 represents an "ideal" skin sampling site based on current dart biopsy targeting practices and live capture/health assessment tissue dissection and collection protocols. Referencing to site D1 allowed the relative concentration data to be combined and evaluated with greater statistical power and accounted for between-animal variability in trace element concentrations expected based on life history information for the individual animals. Fig. (2) displays the compiled relative concentration data as a function of increasing inter-site variability. Mercury, $\mathrm{As}, \mathrm{Cu}$, $\mathrm{Mn}$, Mo and $\mathrm{Zn}$ show a variability of $\pm 25 \%$ or less based on the $95 \%$ confidence intervals. Higher variability elements include $\mathrm{V}, \mathrm{Rb}, \mathrm{Sr}, \mathrm{Pb}$ and $\mathrm{Cd}$ suggests that these elements 
Table 2. Trace Element Concentrations (ng/g, wet mass) in Skin of Bottlenose Dolphin

\begin{tabular}{|c|c|c|c|c|c|c|c|c|c|c|c|c|}
\hline Sample ID & $\mathbf{V}$ & Mn & $\mathbf{C u}$ & $\mathbf{Z n}$ & As & Se & $\mathbf{R b}$ & $\mathrm{Sr}$ & Mo & Cd & $\mathbf{H g}$ & $\mathbf{P b}$ \\
\hline \multicolumn{12}{|c|}{ Florida Animal } & \\
\hline B1 & 10.5 & 49.1 & 465 & 220225 & 269 & 2812 & 869 & 463 & 6.5 & 1.7 & 1913 & 21.0 \\
\hline $\mathrm{B} 2$ & 3.5 & 31.3 & 319 & 100650 & 196 & 2010 & 815 & 218 & 3.4 & 0.4 & 1557 & 3.1 \\
\hline B3 & 3.5 & 33.6 & 394 & 104604 & 254 & 1905 & 854 & 212 & 3.6 & 0.5 & 1866 & 6.9 \\
\hline $\mathrm{Cl}$ & 10 & 50.9 & 568 & 228281 & 306 & 2913 & 988 & 335 & 7.7 & 3.1 & 2095 & 7.8 \\
\hline $\mathrm{C} 2$ & 5.5 & 32.5 & 397 & 138845 & 219 & 2124 & 739 & 264 & 4.9 & 1.3 & 1783 & 5.0 \\
\hline $\mathrm{C} 3$ & 3.8 & 36.0 & 448 & 130218 & 265 & 1892 & 949 & 309 & 3.9 & 5.1 & 1838 & 4.6 \\
\hline Dl & 6.6 & 33.9 & 387 & 129860 & 202 & 2083 & 691 & 207 & 4.9 & 0.8 & 1563 & 6.6 \\
\hline D2 & 5.6 & 24.9 & 365 & 120254 & 192 & 2152 & 657 & 261 & 3.7 & 1.1 & 1761 & 7.0 \\
\hline D3 & 3.5 & 36.1 & 524 & 142050 & 287 & 1970 & 1012 & 269 & 5.0 & 1.4 & 2048 & 4.3 \\
\hline E1 & 5.2 & 26.6 & 404 & 109005 & 186 & 2204 & 780 & 215 & 4.1 & 1.2 & 1692 & 5.1 \\
\hline E2 & 5.7 & 38.6 & 426 & 141170 & 227 & 2264 & 869 & 229 & 4.5 & 0.5 & 1853 & 5.0 \\
\hline E3 & 5.5 & 42.7 & 517 & 167318 & 276 & 2437 & 946 & 370 & 5.6 & 1.1 & 2176 & 8.7 \\
\hline$n$ & 12 & 12 & 12 & 12 & 12 & 12 & 12 & 12 & 12 & 12 & 12 & 12 \\
\hline Mean & 5.8 & 36.4 & 435 & 144373 & 240 & 2230 & 848 & 279 & 4.8 & 1.5 & 1845 & 7.1 \\
\hline SD & 2.4 & 7.97 & 73 & 41674 & 41 & 334 & 115 & 78 & 1.3 & 1.3 & 194 & 4.7 \\
\hline $\mathrm{CV}$ & $40.9 \%$ & $21.9 \%$ & $16.7 \%$ & $28.9 \%$ & $17.2 \%$ & $15.0 \%$ & $13.6 \%$ & $27.9 \%$ & $26.4 \%$ & $88.5 \%$ & $10.5 \%$ & $65.8 \%$ \\
\hline \multicolumn{13}{|c|}{ South Carolina Animal } \\
\hline B1 & 14.3 & 73.2 & 1249 & 211023 & 862 & 9738 & 348 & 1087 & 8.8 & 4.5 & 1850 & 7.3 \\
\hline B2 & 11.4 & 66.1 & 1109 & 171613 & 921 & 8084 & 489 & 932 & 6.5 & 15.2 & 1591 & 6.9 \\
\hline B3 & 6.2 & 39.0 & 1092 & 134906 & 854 & 8011 & 782 & 326 & 4.6 & 2.5 & 1334 & 3.2 \\
\hline $\mathrm{Cl}$ & 12.7 & 44.2 & 1287 & 185860 & 659 & 7223 & 364 & 516 & 7.2 & 1.2 & 1418 & 2.6 \\
\hline $\mathrm{C} 2$ & 9.1 & 72.6 & 1011 & 129885 & 538 & 5559 & 393 & 895 & 7.1 & 32.7 & 1416 & 3.3 \\
\hline $\mathrm{C} 3$ & 3.5 & 38.0 & 1106 & 118331 & 681 & 6564 & 699 & 278 & 4.1 & 5.3 & 1326 & 2.4 \\
\hline Dl & 17.0 & 63.9 & 1183 & 166001 & 636 & 6913 & 332 & 1388 & 9.1 & 4.8 & 1428 & 2.7 \\
\hline D2 & 12.3 & 70.8 & 1131 & 140354 & 546 & 6187 & 491 & 686 & 6.5 & 30.6 & 1317 & 3.1 \\
\hline D3 & 3.4 & 42.5 & 1164 & 124971 & 727 & 7067 & 748 & 315 & 4.0 & 7.7 & 1338 & $50.3^{\mathrm{a}}$ \\
\hline El & 8.7 & 38.9 & 1038 & 140055 & 732 & 6998 & 368 & 645 & 5.4 & 3.1 & 1440 & 2.6 \\
\hline E2 & 18.4 & 75.5 & 1119 & 131699 & 557 & 5551 & 412 & 1370 & 7.5 & 12.7 & 1397 & 3.8 \\
\hline E3 & 12.6 & 59.6 & 1114 & 130736 & 671 & 6601 & 718 & 592 & 5.8 & 3.0 & 1483 & 10.8 \\
\hline$n$ & 12 & 12 & 12 & 12 & 12 & 12 & 12 & 12 & 12 & 12 & 12 & 12 \\
\hline Mean & 10.8 & 57.0 & 1134 & 148786 & 699 & 7041 & 512 & 752 & 6.4 & 10.3 & 1445 & 4.4 \\
\hline SD & 4.8 & 15.3 & 79 & 28405 & 127 & 1165 & 174 & 387 & 1.7 & 10.8 & 149 & 2.7 \\
\hline $\mathrm{CV}$ & $44.5 \%$ & $26.7 \%$ & $6.9 \%$ & $19.1 \%$ & $18.2 \%$ & $16.5 \%$ & $34.0 \%$ & $51.4 \%$ & $26.5 \%$ & $105.2 \%$ & $10.3 \%$ & $61.4 \%$ \\
\hline
\end{tabular}

${ }^{4}$ Sample rejected as outlying and not included in summary statistics calculations.

are more heterogeneously deposited in dolphin skin. It is encouraging that the mercury data showed the least amount of variability of the elements tested, as this element is currently the most targeted trace element for monitoring in dolphin tissue. Relatively high concentration levels of $\mathrm{Hg}$ facilitate analyses of the smaller sample masses collected from remote dart biopsy sampling.
It must be emphasized that the locations chosen to assess across body heterogeneity of trace elements were purposely sampled from diverse body regions that would not necessarily represent the possible dart biopsy or live capture tissue collection locations, but would help answer a fundamental question about the representativeness of dolphin skin as a repository for trace elements. For example, samples 


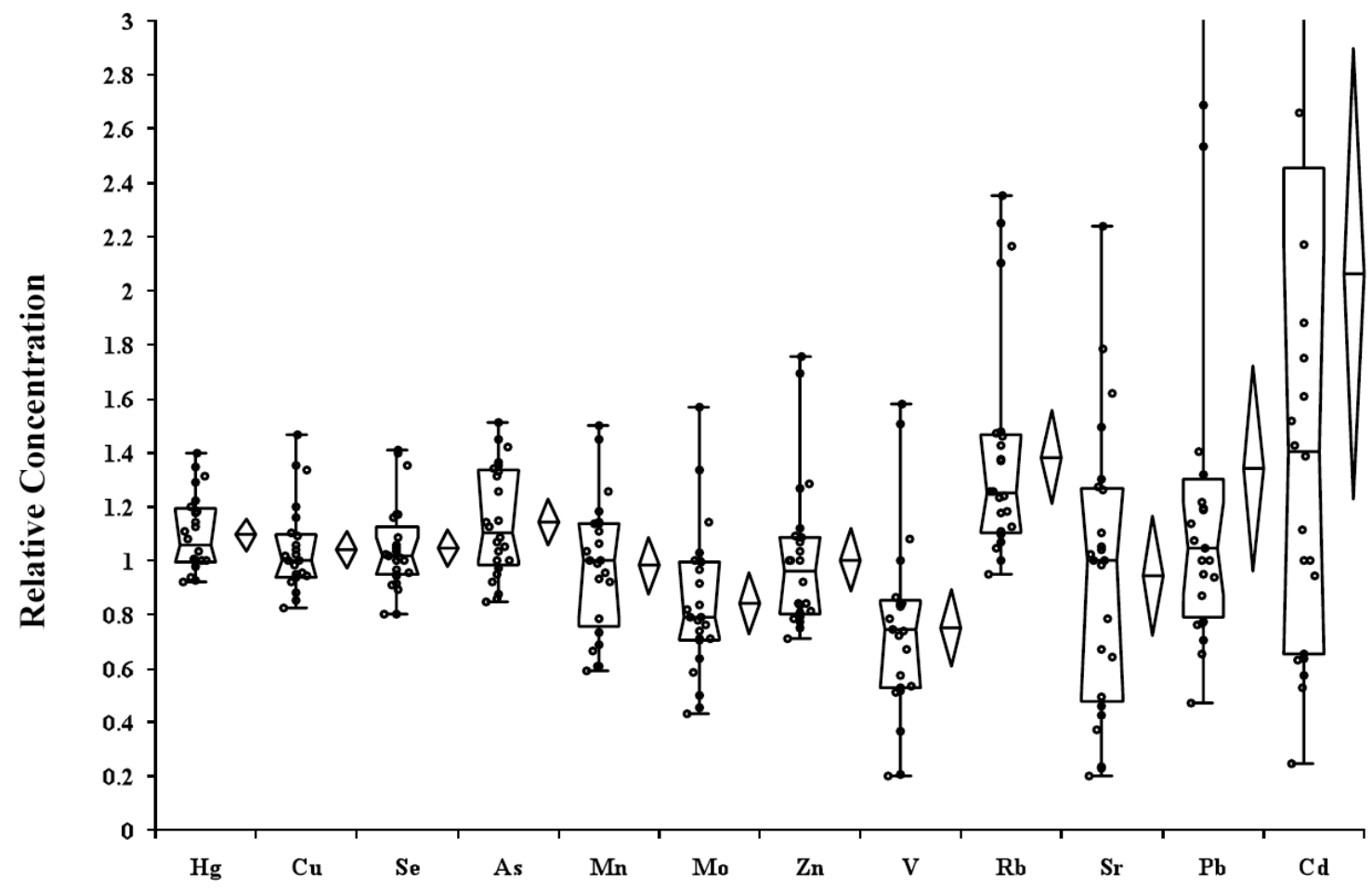

\section{Element}

Fig. (2). Relative trace element concentration data based on referencing absolute concentration data to site D1 as a function of increasing between-sampling site variability. Median box and whisker plots include individual concentration estimates (circles); diamonds represent mean $\pm 95 \%$ C.I. For clarity, some individual data for $\mathrm{Pb}$ and $\mathrm{Cd}$ are purposely left off scale.

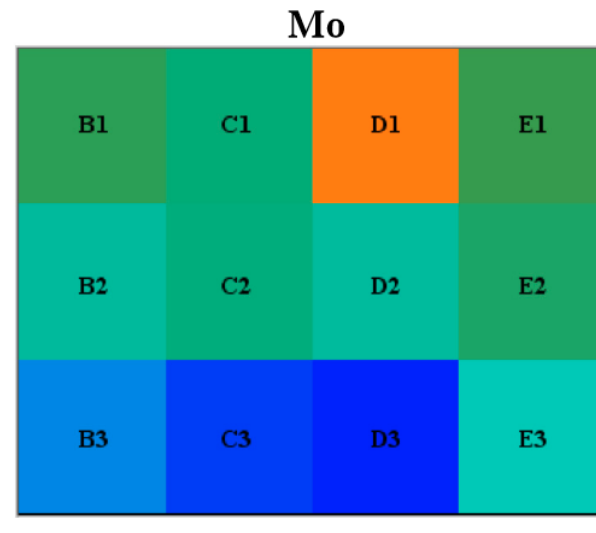

$\mathbf{R b}$
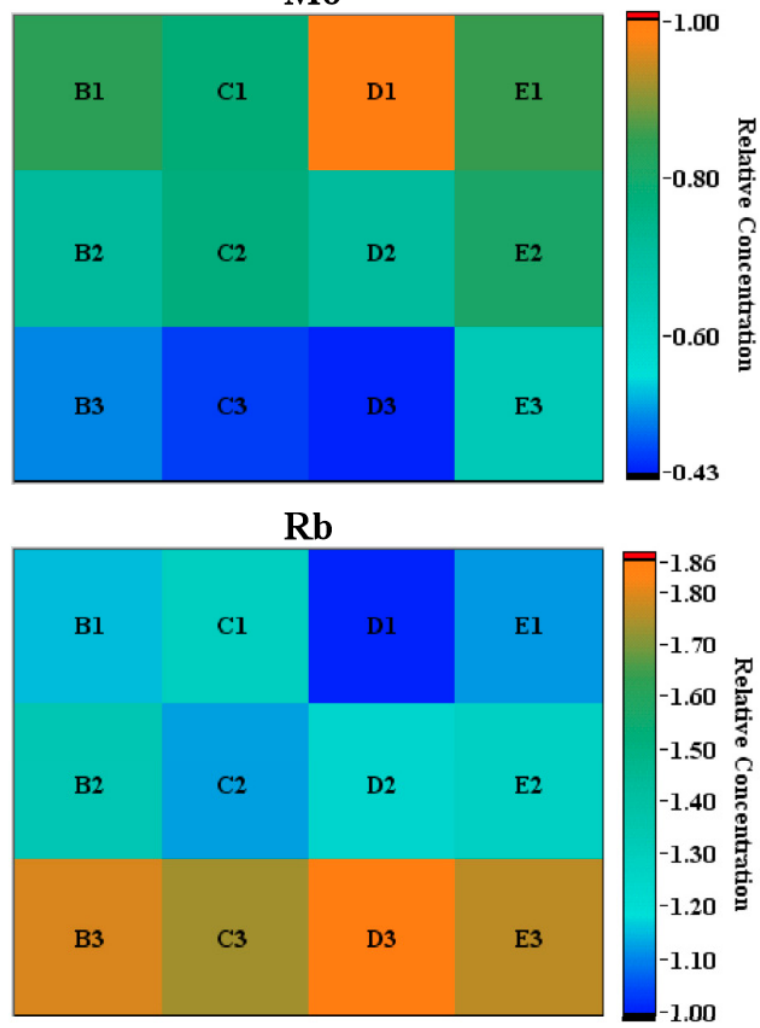

0.43
V

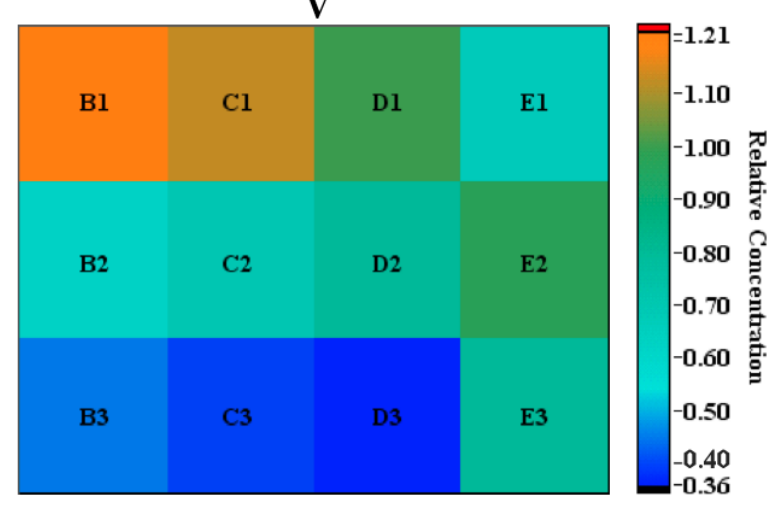

$\mathrm{Zn}$

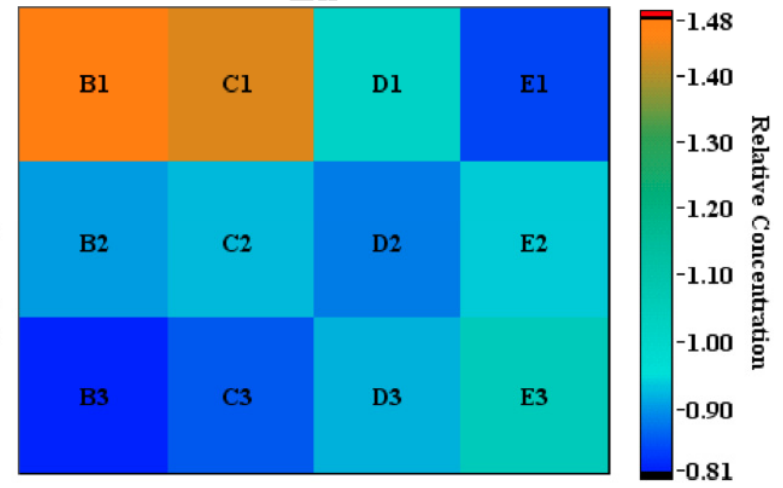

Fig. (3). Spatial representation of relative concentration data portrayed as color intensity maps for elements with significant longitudinal effects (dorsal-ventral). Each color block represents the trace element concentration relative to the concentration of D1 (target biopsy location). The color blocks are organized in the same grid pattern as they were biopsied from the animals as shown in Fig. (1). 
collected from the underbelly ventral region (plane 3, Fig. 1) would not be accessible via dart strike or live capture tissue sampling as these sampling approaches are necessarily biased towards sampling toward dorsal side of the animal, rather the data can shed light on trace element spatial concentration variability. Concentration data appears to be element specific, and greater sampling could provide greater statistical strength that may provide insight on the function, structure, and chemistry of trace elements in marine mammal skin. Effects of lateral body planes (Fig. 1, represented by letters) and longitudinal body planes (Fig. 1, represented numerically) were explored for each trace element by mixedeffect ANOVA (Table 3). Lateral differences in concentration were not observed for any of the elements studies. Molybdenum, $\mathrm{Rb}, \mathrm{V}$, and $\mathrm{Zn}$ all exhibited statistically significant longitudinal effects. Copper and Se exhibited marginally significant longitudinal effects and differences were not detected between planes using HSD statistical tests. Spatial representation of relative concentration data for elements with significant longitudinal effects are portrayed in Fig. (3) using color intensity maps. Molybdenum and $\mathrm{V}$ concentrations in plane 3 on the ventral side of the animals were statistically lesser than planes 1 and 2 , which had comparable concentrations. Rubidium concentrations in plane 3 were statistically greater than the similar concentrations of planes 1 and 2. Zinc concentrations in plane 1 were greater than planes 2 and 3 , which had similar concentrations. Plane 1 on the dorsal side of a bottlenose dolphin is expected to be more exposed to the sun, allowing the possibility for skin in this region to be subjected to greater ultraviolet solar damage [26]. Significantly greater $\mathrm{Zn}$ concentrations in plane 1 may be involved in protective functions against solar radiation. Fujise et al. [18] analyzed trace elements in skin from two regions of Dall's porpoise: black skin from the dorsal side and white skin from the ventral side. Their study did not address any statistical difference between trace element concentrations from the two skin sample sites, but the $\mathrm{Zn}$ deposition pattern in Dall's porpoise was similar to bottlenose dolphins in this study, where concentrations were greater on the dorsal region (black skin) than the ventral side (white skin). Gross differences in skin thickness were not visually observed in the sampling regions from each animal and full-depth skin samples were used in trace element analyses. Skin anatomy studies by Harrison and Thurley [27] and Colbert et al. [28] also found no significant differences in epidermis depth from an individual bottlenose dolphin among anatomic sites similar to those sampled in this study. Differences in the resultant trace element concentrations among locations were more likely dependent on animal physiology, rather than skin thickness and sample mass. Longitudinal effect results preliminarily indicate that for certain elements, skin samples may need to be collected from a standardized region to allow for valid inter-study comparisons of concentrations for multiple trace elements among individuals, populations, and species. Greater statistical sampling would be required to definitively validate the concentration trends discovered in this paper. However, live capture and release sampling efforts for bottlenose dolphin health assessments along the Atlantic and Gulf of Mexico coasts have already implemented standardized protocols developed by NIST and associated researchers that uniformly collect a wedge biopsy from an individual animal approximately $10 \mathrm{~cm}$ posterior and $10 \mathrm{~cm}$ ventral from the posterior aspect of the dorsal fin.

Table 3. Results from Multifactor Mixed-Effect ANOVAs for Trace Elements Determined in Bottlenose Dolphin Skin

\begin{tabular}{|c|c|c|}
\hline \multirow{2}{*}{ Element } & \multicolumn{2}{|c|}{$p$-Value } \\
\cline { 2 - 3 } & $\begin{array}{c}\text { Lateral Effect } \\
\text { (Anterior- Posterior) }\end{array}$ & $\begin{array}{c}\text { Longitudinal Effect } \\
\text { (Dorsal-Ventral) }\end{array}$ \\
\hline \hline $\mathrm{As}^{\mathrm{a}}$ & 0.2156 & 0.0690 \\
\hline $\mathrm{Cd}^{\mathrm{a}}$ & 0.5552 & 0.4457 \\
\hline $\mathrm{Cu}^{\mathrm{a}}$ & 0.5896 & $0.0408^{*}$ \\
\hline $\mathrm{Hg}$ & 0.7113 & 0.5147 \\
\hline $\mathrm{Mn}{ }^{\mathrm{a}}$ & 0.9467 & 0.4351 \\
\hline $\mathrm{Mo}$ & 0.9577 & $0.0106^{*}$ \\
\hline $\mathrm{Pb}^{\mathrm{a}}$ & 0.1968 & 0.6335 \\
\hline $\mathrm{Rb}$ & 0.9313 & $0.0013^{*}$ \\
\hline $\mathrm{Se}^{\mathrm{a}}$ & 0.2077 & $0.0493^{*}$ \\
\hline $\mathrm{Sr}^{\mathrm{a}}$ & 0.9141 & 0.1474 \\
\hline $\mathrm{V}^{\mathrm{a}}$ & 0.5539 & $0.0011^{*}$ \\
\hline $\mathrm{Zn}^{\mathrm{a}}$ & 0.5549 & $0.0186^{*}$ \\
\hline$* \mathrm{Significn|}^{\mathrm{i}}$ & & \\
\hline
\end{tabular}

*Significant effect $p<0.05$.

${ }^{a}$ Natural log transformed to meet the requirement of normality.

\section{CONCLUSIONS}

Collision cell ICP-MS was used to assess trace element concentrations in skin of bottlenose dolphins to explore the across body homogeneity and distribution of trace elements in order to explore the validity of employing skin as a nonlethal monitoring tissue. Given the difficult analytical problem of the limited sample mass available from skin biopsies, the large number of elements requiring measurement, and their wide concentration ranges, multiple mode CCT-ICP-MS analyses in combination with the method of standard additions facilitated high accuracy concentration measurements for multiple elements from a single sample digest and allowed high sample throughput. The results showed that $\mathrm{Zn}$ possessed the greatest concentration for the elements studied; indicating $\mathrm{Zn}$ could be an important element for skin physiology and health target. Vanadium, $\mathrm{Mo}, \mathrm{Cd}$, and $\mathrm{Pb}$ exhibited low concentrations compared to other trace elements measured. The variability of trace element deposition in skin was element dependent and sampling schemes that normalize to body location should be considered when designing an experiment. For intact, internal organs such as the kidney, heterogeneity at the whole organ level is not an analytical problem since the entire organ can be homogenized to ensure homogeneity of sub-samples. In order to use skin as a nonlethal monitoring tissue, only the elements that are homogenous across an animal's body can be comparatively evaluated unless a standardized location is routinely used to collect biopsies for trace element analyses. Molybdenum, $\mathrm{Rb}, \mathrm{V}$, and $\mathrm{Zn}$ exhibited significant longitudinal effects 
while $\mathrm{Cd}, \mathrm{Cu}, \mathrm{Hg}, \mathrm{Mn}, \mathrm{Pb}$, and $\mathrm{Sr}$ concentrations were homogenous in skin across the body regions sampled. Although it may not be possible for every marine mammal species, adoption of a standardized skin collection region would assist with comparing trace element data for a broad suite of elements among disparate bottlenose dolphin sampling efforts and possibly for other cetacean or pinneped live capture and release studies. Elements that exhibited homogenous concentrations in skin across the body could be effectively collected by dart biopsy using a full depth skin sample without body location confounding the results. Dart biopsy collection to examine trace elements that are not homogeneously deposited would require data to be normalized by site location.

Future studies will include examining the minimum dart biopsy sample mass needed to accurately measure individual trace element concentrations. Consistently using the same sample mass eliminates concern for micro-homogeneity interfering with macro-homogeneity analysis of trace elements in cetacean skin. Dart biopsies provide limited skin sample mass that may not be representative of bulk skin and the sample size may restrict determination of trace elements present at ultra low concentrations due to analytical instrumentation detection limits.

\section{ACKNOWLEDGEMENTS}

John Kucklick, NIST Charleston, SC, and Ann Pabst, University of North Carolina Wilmington, are acknowledged for providing assistance with sample collection and experimental design. Rebecca Pugh and Michael Ellisor, NIST Charleston, SC, are greatly appreciated for help with cryohomogenization and sample banking. Terrie Butler, NIST Gaithersburg, MD, is acknowledged for assistance with the preparation of custom multi-element spike solutions. Teresa Rowles, NOAA, is thanked for providing support for these studies under the Marine Mammal Health and Stranding Response Program.

\section{DISCLAIMER}

Certain commercial products and instruments are identified in this paper to adequately specify the experimental procedures. Such identification does not imply recommendation or endorsement by the National Institute of Standards and Technology. Nor does it imply that the items mentioned are the best for the intended purpose.

\section{REFERENCES}

[1] Yang, Y.; Kunito, T.; Tanabe, S.; Amano, M.; Miyazaki, N. Trace elements in skin of Dall's porpoises (Phocoenoides dalli) from the northern waters of Japan: an evaluation for utilization as non-lethal tracers. Mar. Pollut. Bull., 2002, 45, 230-236.

[2] Reynolds, J. E.; Wells, R. S.; Eide, S. D. The Bottlenose Dolphin: Biology and Conservation; University of Florida Press: Gainesville, FL, 2000.

[3] Hoelzel, A. R. Marine Mammal Biology: An Evolutionary Approach; Blackwell Science: Malden, MA, 2002; pp. 73-97.

[4] Wagemann, R.; Innes, S.; Richard, P. R. Overview and regional and temporal differences of heavy metals in Arctic whales and ringed seals in the Canadian Arctic. Sci. Total Environ., 1996, 186 (1-2), 41-66.

[5] Wagemann, R.; Kozlowska, H. Mercury distribution in the skin of beluga (Delphinapterus leucas) and narwhal (Monodon monoceros) from the Canadian Arctic and mercury burdens and excretion by moulting. Sci. Total Environ., 2005, 351, 333-343.
[6] Thompson, D. R. Heavy Metals in Marine Vertebrates; CRC Press: Boca Raton, 1990, pp. 143-182.

[7] Hicks, B. D.; Staubin, D. J.; Geraci, J. R.; Brown, W. R. Epidermal growth in the bottlenose dolphin, Tursiops truncatus. J. Invest. Dermatol., 1985, 85 (1), 60-63.

[8] Kunito, T.; Watanabe, I.; Yasunaga, G.; Fujise, Y.; Tanabe, S. Using trace elements in skin to discriminate the populations of minke whales in southern hemisphere. Mar. Environ. Res., 2002, 53 (2), 175-197.

[9] Monaci, F.; Borrel, A.; Leonzio, C.; Marsili, L.; Calzada, N. Trace elements in striped dolphins (Stenella coeruleoalba) from the western Mediterranean. Environ. Pollut., 1998, 99 (1), 61-68.

[10] Bryan, C. E.; Christopher, S. J.; Balmer, B. C.; Wells, R. S. Establishing baseline levels of trace elements in blood and skin of bottlenose dolphins in Sarasota Bay, Florida: implications for noninvasive monitoring. Sci. Total Environ., 2007, 388 (1-3), 325-342.

[11] Stavros, H. C. W.; Bossart, G. D.; Hulsey, T. C.; Fair, P. A. Trace element concentrations in skin of free-ranging bottlenose dolphins (Tursiops truncatus) from the southeast Atlantic coast. Sci. Total Environ., 2007, 388 (1-3), 300-315.

[12] Reddy, M.; Echols, S.; Finklea, B.; Busbee, D.; Reif, J. PCBs and chlorinated pesticides in clinically healthy Tursiops truncatus: relationships between levels in blubber and blood. Mar. Pollut. Bull., 1998, 36 (11), 892-903.

[13] Reddy, M. L.; Reif, J. S.; Bachand, A.; Ridgway, S. H. Opportunities for using Navy marine mammals to explore associations between organochlorine contaminants and unfavorable effects on reproduction. Sci. Total Environ., 2001, 274 (1-3), 171182 .

[14] Wells, R. S.; Rhinehart, H. L.; Hansen, L. J.; Sweeney, J. C.; Townsend, F. I.; Stone, R.; Casper, D. R.; Scott, M. D.; Hohn, A. A.; Rowles, T. K. Bottlenose dolphins as marine ecosystem sentinels: developing a health monitoring system. EcoHealth, 2004, 1, 246-254.

[15] Wells, R. S.; Tornero, V.; Borrell, A.; Aguilar, A.; Rowles, T. K.; Rhinehart, H. L.; Hofmann, S.; Jarman, W. M.; Hohn, A. A.; Sweeney, J. C. Integrating life-history and reproductive success data to examine potential relationships with organochlorine compounds for bottlenose dolphins (Tursiops truncatus) in Sarasota Bay, Florida. Sci. Total Environ., 2005, 349 (1-3), 106119.

[16] Schwacke, L. H.; Voit, E. O.; Hansen, L. J.; Wells, R. S.; Mitchum, G. B.; Hohn, A. A.; Fair, P. A. Probabilistic risk assessment of reproductive effects of polychlorinated biphenyls on bottlenose dolphins (Tursiops trucatus) from the southeast United States coast. Environ. Toxicol. Chem., 2002, 21 (12), 2752-2764.

[17] Christopher, S. J.; Day, R. D.; Bryan, C. E.; Turk, G. C. Improved calibration strategy for measurement of trace elements in biological and clinical whole blood reference materials via collision-cell inductively coupled plasma mass spectrometry. J. Anal. At. Spectrom., 2005, 20, 1035-1043.

[18] Fujise, Y.; Honda, K.; Tatsukawa, R.; Mishima, S. Tissue distribution of heavy-metals in Dalls porpoise in the northwestern Pacific. Mar. Pollut. Bull., 1988, 19 (5), 226-230.

[19] Honda, K.; Tatsukawa, R. Distribution of cadmium and zinc in tissues and organs and their age-related changes in striped dolphins, Stenella coeruleoalba. Arch. Environ. Contam. Toxicol., 1983, 12 (5), 543-550.

[20] Bang, R. L.; Al-Bader, A. L.; Sharma, P. N.; Mattapallil, A. B.; Behbehani, A. I.; Dashti, H. Trace elements content in serum, normal skin, and scar tissues of keloid and normal scar patients. $J$. Trace Elem. Exper. Med., 2002, 15 (1), 57-66.

[21] Gonul, B.; Soylemezoglu, T.; Babul, A.; Celebi, N. Effects of epidermal growth factor dosage forms on mice full-thickness skin wound zinc levels and relation to wound strength. J. Pharm. Pharmacol., 1998, 50 (6), 641-644.

[22] Urian, K. W.; Wells, R. S.; Scott, M. D.; Irvine, A. B.; Read, A. J.; Hohn, A. A. In: When the Shark Bites: An Analysis of Shark Bite Scars on Wild Bottlenose Dolphins; (Tursiops truncatus) from Sarasota, Florida, World Marine Mammal Science Conference, Monaco, 1998

[23] Wells, R. S.; Scott, M. D.; Irvine, A. B. The Social Structure of Free-Ranging Bottlenose Dolphins. Plenum Press: New York, NY, 1987, Vol. 1 .

[24] Emonet, N.; Leccia, M. T.; Favier, A.; Beani, J. C.; Richard, M. J. Thiols and selenium: protective effect on human skin fibroblasts 
exposed to UVA radiation. J. Photochem. Photobiol. B, Biol., 1997, $40(1), 84-90$

[25] Andre, J. M.; Boudou, A.; Ribeyre, F. Mercury accumulation in delphinidae. Water Air Soil Pollut., 1991, 56, 187-201.

[26] Geraci, J. R.; St. Aubin, D. J.; Hicks, B. D. The Epidermis of Odontocetes: A View from within; Clarendon Press: Oxford, England, 1986.
[27] Harrison, R. J.; Thurley, K. S., Structure of the Epidermis in Tursiops, Delphinus, Orcinus and Phocoena; Academic Press: London, England, 1974; Vol. 2.

[28] Colbert, A.; Stoskopf, M.; Brownie, C.; Scott, G. I.; Levine, J., Anatomic site and interanimal variability in morphologic characteristics of bottlenose dolphin (Tursiops truncatus) skin likely to affect dermal absorption studies. Am. J. Vet. Res., 1998, 59 (11), 1398-1403.

(C) Bryan et al.; Licensee Bentham Open.

This is an open access article licensed under the terms of the Creative Commons Attribution Non-Commercial License (http://creativecommons.org/licenses/by$\mathrm{nc} / 3.0 /$ ) which permits unrestricted, non-commercial use, distribution and reproduction in any medium, provided the work is properly cited. 